\title{
Construção e validação de uma tecnologia educacional para prevenção da siffilis congênita
}

Construction and validation of an educational technology for the prevention of congenital syphilis Elaboración y validación de una tecnología educativa para prevención de sífilis congénita

Camila Chaves da Costa ${ }^{1}$ io https://orcid.org/0000-0001-8582-6992

Linicarla Fabíole de Souza Gomes ${ }^{2}$ id https://orcid.org/0000-0002-8124-5231

Liana Mara Rocha Teles ${ }^{2}$ io https://orcid.org/0000-0002-8124-5231

Igor Cordeiro Mendes² id https://orcid.org/0000-0002-9414-8924

Mônica Oliveira Batista Oriá2 io https://orcid.org/0000-0002-1483-6656

Ana Kelve de Castro Damascen² io https://orcid.org/0000-0003-4690-9327

\section{Como citar:}

Costa CC, Gomes LF, Teles LM, Mendes

IC, Oriá MO, Damasceno AK. Construção e

validação de uma tecnologia educacional

para prevenção da sifilis congênita. Acta Paul Enferm. 2020;33:eAPE20190028.

DOI

http://dx.doi.org/10.37689/actaape/2020A000286

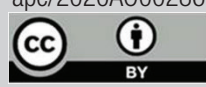

em saúde; Tecnologia educacional; Transmissão vertical de doença infecciosa

Keywords

Syphilis, congenital; Health education: Educationa technology; Infectious disease transmission,

vertical

Descriptores

Sifilis congénita; Educación en salud; Tecnología educacional; Transmisión vertical de enfermedad infecciosa

\section{Submetido}

7 de Fevereiro de 2019

Aceito

8 de Abril de 2020

Autor correspondente

Camila Chaves da Costa

E-mail: camilachaves@unilab.edu.br

\section{Resumo}

Objetivo: Construir e validar a cartilha educativa intitulada "Como prevenir a transmissão da sífilis de mãe para filho? Vamos aprender!".

Métodos: Pesquisa metodológica, associada a um estudo quase experimental, conduzida de acordo com as seguintes fases: elaboração da cartilha educativa; validação de aparência e conteúdo com 22 juízes e 11 mulheres com diagnóstico de sífilis na gestação; e a avaliação dos efeitos no Conhecimento, Atitude e Prática de 41 gestantes antes e após a leitura da cartilha educativa durante.

Resultados: Validou-se a cartilha quanto à aparência e conteúdo, com o Índice de Validade de Conteúdo (IVC) Global de 0,96, Alfa de Cronbach total de 0,955 e validação dos juízes pelo Suitability Assessment of Materials considerada "superior". Quanto à validação pelo público-alvo, obteve 100\% de concordância e um IVC global de 1,00. 0 Flesch Legibility Test considerou a leitura Muito Fácil ou Fácil. Verificou-se um aumento da porcentagem de mulheres classificadas com um conhecimento, atitude e prática adequados após a leitura da cartilha. Essa mudança na prática foi estatisticamente significativa $(p=0,002)$, demonstrando que a leitura da cartilha educativa se mostrou efetiva para promover mudanças comportamentais.

Conclusão: 0 material construído é confiável e validado por especialistas e pelo público-alvo, como também eficaz para promover a melhoria do CAP das gestantes visando à prevenção da transmissão vertical da sífilis.

\section{Abstract}

Objective: To construct and validate the educational booklet entitled "How to prevent the transmission of syphilis from mother to child? Let's learn!".

Methods: Methodological, quasi-experimental study conducted according to the following steps: development of the educational booklet; face and content validation with 22 judges and 11 women diagnosed with syphilis during pregnancy; and evaluation of the effects on the Knowledge, Attitude and Practice (KAP) of 41 pregnant women before and after reading the educational booklet.

Results: The booklet was submitted to face and content validation with an Overall Content Validity Index (CVI) of 0.96 , a total Cronbach's alpha of 0.955 . The validation of judges by the Suitability Assessment of Materials was considered "superior". As for validation by the target audience, it obtained $100 \%$ concordance and an overall CVI of 1.00. According to the Flesch Reading Ease (FRE) test, reading was considered Very Easy or Easy. There was an increase in the percentage of women classified as having appropriate knowledge, attitude and practice after reading the booklet. This change in practice was statistically significant $(p=0.002)$, demonstrating that reading the educational booklet proved to be effective in promoting behavioral changes. 
Conclusion: The material constructed is reliable and validated by specialists and the target audience and effective in promoting the improvement of the KAP of pregnant women with the aim to prevent vertical transmission of syphilis.

\section{Resumen}

Objetivo: Elaborar y validar una cartilla educativa titulada “¿Cómo prevenir la transmisión de la sífilis de madre a hijo? ¡Vamos a aprender!”.

Métodos: Investigación metodológica, asociada a un estudio cuasi experimental, llevada a cabo de acuerdo con las siguientes fases: elaboración de la cartilla educativa, validación de la apariencia y contenido por 22 jueces y 11 mujeres con diagnóstico de sífilis en el embarazo, y evaluación de los efectos en el conocimiento, las actitudes y la práctica de 41 mujeres embarazadas antes y después de la lectura de la cartilla educativa.

Resultados: Se validó la cartilla con relación a la apariencia y contenido, con un Índice de Validez de Contenido (IVC) global de 0,96, un alfa de Cronbach total de 0,955 y la validación de los jueces mediante el Suitability Assessment of Materials fue considerada "superior". Respecto a la validación del público destinatario, se obtuvo un 100 \% de concordancia y un IVC global de 1,00. A través del Flesch Legibility Test, la lectura se consideró "muy fácil" o "fácil". Se verificó un aumento del porcentaje de mujeres clasificadas con conocimiento, actitud y práctica adecuados después de la lectura de la cartilla. En la práctica, este cambio fue estadísticamente significativo $(p=0,002)$, lo que evidencia que la lectura de la cartilla educativa demostró ser efectiva para promover cambios de comportamiento.

Conclusión: El material elaborado es confiable y fue validado por especialistas y por el público destinatario, así como también es eficaz para promover la mejora de los CAP de las mujeres embarazadas con el objetivo de prevenir la transmisión vertical de la sífilis.

\section{Introdução}

A sífilis congênita é um importante problema de saúde pública, constituindo-se como fator determinante na elevação dos indicadores de morbimortalidade materna e perinatal, apesar de tratar-se de uma doença de fácil diagnóstico e de ser totalmente evitável quando o tratamento da gestante e de seu parceiro é realizado adequadamente.

No Brasil, o coeficiente de mortalidade infantil por sífilis no ano de 2017 foi de 7,2 por 100.000 nascidos vivos. $\mathrm{O}$ número de casos de sífilis congênita está cada vez mais incidente, havendo um progressivo aumento na taxa de incidência de sífilis congênita, saltando de 2,0 casos/mil nascidos vivos em 2007 para 8,6 casos/mil nascidos vivos em $2017,^{(1)}$ sendo imprescindível a criação de novas estratégias que possibilitem a atuação nas reais lacunas que impossibilitam o almejado controle desse agravo, como a criação de tecnologias educativas que permitam a sensibilização e o empoderamento das mulheres e de seus parceiros quanto à importância de sua participação ativa nesse processo.

O Enfermeiro é um dos grandes responsáveis pela atenção ao pré-natal de baixo risco no Sistema Único de Saúde - SUS e em sua formação está intrínseca, entre outras habilidades, a de atuar como promotor de saúde. $\mathrm{O}$ processo de empoderamento da gestante e de seu parceiro quanto à sífilis congênita requer a utilização de estratégias educativas que possibilitem escolhas informadas, que concorram a um comportamento saudável. Nesse cenário, di- versos recursos, metodologias e técnicas podem ser utilizados para a facilitação do processo educativo.

Dentre as tecnologias educativas, as cartilhas podem ser consideradas um eficiente meio de comunicação para promover a saúde. Além de contribuir para o empoderamento do usuário, a cartilha permite que o mesmo atue como multiplicador, apresentando o material a outros sujeitos da comunidade. As cartilhas são materiais impressos úteis para descrição de assuntos relacionados à saúde, sendo possível sua utilização como instrumento de promoção da saúde, facilitador do processo educativo e melhoria do conhecimento, atitude e prática - CAP dos leitores. ${ }^{(2,3)}$

Em busca ampla na literatura, verificou-se a escassez de pesquisa metodológica envolvendo a temática sífilis congênita, com a predominância de estudos epidemiológicos. Adicionam-se a tal problemática a magnitude e repercussóes da sífilis congênita, a necessidade de empoderamento das gestantes para o controle desse agravo e a importância de tecnologias educativas direcionadas a esse público-alvo.

Dessa forma, a construção, validação e mensuração dos efeitos da cartilha educativa no CAP das gestantes sobre a temática são relevantes para implantação dessa tecnologia como recurso metodológico para práticas educativas realizadas por enfermeiros no atendimento pré-natal. Ademais, possibilitam a multiplicação dos conhecimentos de uma gestante para outra, a sensibilização do parceiro e a fixação do conhecimento adquirido, posto que a cartilha poderá ser consultada quantas vezes forem necessárias.

Diante do exposto, objetivou-se construir e validar a cartilha educativa intitulada "Como prevenir 
a transmissão da sífilis de mãe para filho? Vamos aprender!”.

\section{Métodos}

Estudo metodológico e quase-experimental, desenvolvido em três fases: elaboração da cartilha educativa; validação de aparência e conteúdo; e avaliação dos efeitos da utilização da cartilha como estratégia educativa no pré-natal para a melhoria do CAP das gestantes acerca da prevenção da transmissão vertical da sífilis. Todas as etapas foram desenvolvidas entre os meses de junho e setembro de 2016.

Para a construção desse material educativo, seguiram-se as seguintes etapas: levantamento bibliográfico (seleção, organização cronológica e coerente do conteúdo); elaboração do material educativo (elaboração textual, confecção das ilustraçóes e diagramação); e validação do material por especialistas no assunto e representantes do público-alvo. ${ }^{(4)}$

Embasou-se o conteúdo da cartilha em 5 publicaçóes do Ministério da Saúde ${ }^{(5-9)}$ e 20 artigos científicos selecionados mediante uma revisão integrativa; em seguida, definiram-se as principais informaçóes e ilustraçôes pertinentes ao tema, para organizá-las de forma sistemática e sequencial.

Utilizaram-se referenciais teóricos e metodológicos que ressaltam elementos que devem ser considerados na elaboração de materiais educativos impressos objetivando a melhor compreensão dos leitores; ${ }^{(10,11)}$ e as ilustraçóes e diagramação da cartilha foram realizadas por profissional capacitado na área de design.

Após a construção da primeira versão, submeteu-se a cartilha para o processo de validação de conteúdo e aparência por um grupo de 22 juízes, ${ }^{(12)}$ sendo recrutados e selecionados de acordo com os critérios descritos por Jasper ${ }^{(13)}$ e por meio da amostragem de rede. Os 55 juízes que atingiram a pontuação mínima foram selecionados por meio da Plataforma Lattes do portal do Conselho Nacional de Desenvolvimento Científico e Tecnológico (CNPq) e convidados a participar do estudo através de Carta Convite, via correio eletrônico ou pessoalmente; em seguida, aqueles que aceitaram participar da pesquisa receberam o instrumento de validação das figuras e dos textos mediante três critérios: clareza da linguagem, pertinência prática e relevância teórica, acrescido do instrumento Suitability Assessment of Materials - SAM para avaliar a compreensão do material educativo. ${ }^{(14)}$

Para análise da validade de conteúdo da cartilha, utilizou-se o Índice de Validade de Conteúdo - IVC, calculado com base em duas equaçóes matemáticas: I-CVI - Level Content Validity Index e o S-CVI - Scale Level Contend Validity Índex. ${ }^{(15)} \mathrm{O}$ IVC varia de 0 a 1 e considera-se válido o item cuja concordância entre os juízes seja $\geq$ que 0,80 . ${ }^{(16)}$

Utilizou-se o teste exato de distribuição binominal para estimar proporçáo de juízes que concordaram com a pertinência dos itens descritos na cartilha, considerando-se pertinente a proporção de 0,8 de concordância. Para análise da consistência interna na opiniâo dos juízes a respeito das questôes adotou-se o teste de coeficiente Alfa de Cronbach, com valor mínimo aceitável de $0,7 .{ }^{(17)}$

Para a análise do SAM, o qual é composto por 22 itens distribuídos em seis domínios de avaliação: conteúdo; linguagem adequada para população; ilustraçôes gráficas; layout e tipografia; estimulação para aprendizagem e motivação; e adequação cultural, atribuiu-se para cada item a classificação de "superior", "adequado" ou "inadequado". ${ }^{(18)}$

Posteriormente, procedeu-se à avaliação descritiva e qualitativa das sugestóes dos juízes, as quais se acatou a maioria, estabelecendo-se a versão para ser implementada com o público-alvo.

Para a validação de conteúdo e aparência com o público-alvo, aplicou-se um instrumento para avaliar os seguintes domínios da cartilha: compreensão; atratividade; autoeficácia; aceitabilidade cultural; e persuasão do material educativo. Além disso, avaliou-se a concordância e a relevância de cada página. ${ }^{(19)}$ Realizou-se essa etapa em uma maternidade de referência do Estado do Ceará, na qual se selecionou aleatoriamente uma amostra de 11 mulheres, ${ }^{(20,21)}$ a partir dos seguintes critérios de inclusão: gestantes ou puérperas com VDRL reagente; as gestantes estarem realizando acompanhamento pré-natal ou as puérperas estarem no alojamento conjunto da instituição. Excluiu-se as mulheres com problemas mentais, cognitivos ou qualquer doença incapacitante que prejudicasse a leitura da cartilha e a comunicaçáo com a pesquisadora. Destaca-se que a 
validação da cartilha com os indivíduos que vivenciam ou já vivenciaram o tema nela abordado é uma atitude necessária, visto que eles são o foco da atividade educativa que se pretende realizar. ${ }^{(22)} \mathrm{A}$ análise dos dados deu-se a partir do Índice de Concordância - IC entre os participantes, sendo considerados validados os itens que obtiveram IC mínimo de $80 \%$. $^{(15)}$

Aplicou-se o Índice de Legibilidade de Flesch - ILF para garantir o uso de uma linguagem coerente para o público-alvo. Para a aplicação do teste, utilizou-se o Revisor Gramatical Automático para o Português - ReGra, que identifica a estrutura sintática da sentença. Aceitou-se para a presente cartilha um ILF de 50 a 100\%, permitindo uma leitura fá$\mathrm{cil} /$ muito fácil, correspondendo a uma escolaridade mínima da quarta série do ensino fundamental. ${ }^{(23)}$

Em seguida, utilizou-se a leitura da cartilha pela pesquisadora com as gestantes, como uma intervenção educativa durante a assistência pré-natal, sensibilizando-as quanto à importância da prevenção da transmissão vertical da sífilis. Avaliaram-se os efeitos dessa intervenção a partir da comparação dos resultados quanto ao CAP das participantes, antes da intervenção, imediatamente após a intervençáo e com sete dias após a realização da mesma por contato telefônico.

A população considerada para essa etapa do estudo foi composta pelas gestantes atendidas em uma unidade de saúde que sedia açóes integradas e multidisciplinares de ensino, pesquisa e extensão e oferta gratuitamente atendimento à população localizada no município de Fortaleza-Ceará. Considerou-se como critério de inclusão as gestantes estarem realizando acompanhamento pré-natal no serviço de saúde selecionado durante o período de coleta de dados. Excluíram-se as mulheres com problemas mentais, cognitivos ou qualquer doença incapacitante que prejudicasse a leitura da cartilha e a comunicação com a pesquisadora. Assim sendo, considerou-se a amostra de 41 gestantes, estimada pelo teste de Qui-quadrado de $\mathrm{McNemar}$. Inicialmente, participaram do pré-teste e do pós-teste imediato 41 gestantes. No entanto, no pós-teste do 70 dia, participaram 38 gestantes, visto que três não atenderam ao contato telefônico realizado repetidas vezes e em horários variados.

As participantes responderam ao pós-teste com as mesmas perguntas do pré-teste, possibilitando descobrir os efeitos da intervenção educativa ao comparar o seu desempenho. O inquérito CAP construído e validado para este estudo, seguiu as seguintes definiçôes: conhecimento classificado como adequado quando a mulher obteve quatro a sete acertos, considerando um total de sete questóes; atitude adequada quando ao responder seis itens tipo Likert com cinco níveis ordinais (concordo plenamente, concordo em parte, não tenho opinião, discordo em parte e discordo plenamente), a gestante demonstrou atitude favorável em pelo menos quatro deles; e a prática adequada quando, ao serem indagadas sobre a realização de quatro recomendaçóes do MS para a prevenção da sífilis congênita, as gestantes afirmaram realizar pelo menos três delas. Tais dados receberam uma análise exploratória.

Houve aprovação do estudo pelo Comitê de Ética em Pesquisa da Universidade Federal do Ceará, segundo o parecer no 1.615.683, obedecendo à Resolução No 466/12. Salienta-se que tal tecnologia está registrada na Câmara Brasileira do Livro, com ISBN 978-65-00-00278-2.

\section{Resultados}

Durante a construção da cartilha educativa, teve-se o cuidado de torná-la acessível e adequada ao público-alvo, organizando as informaçóes pertinentes ao assunto de forma simples e objetiva. Utilizaram-se ilustraçôes para tornar as informaçóes mais atrativas e esclarecedoras, possibilitando a elaboração de um material educativo facilitador do processo de educação em saúde, abordando o conteúdo com uma sequência lógica e com adaptação aos saberes culturais do leitor. Organizou-se o conteúdo abordado a partir dos seguintes domínios: Apresentação; $\mathrm{O}$ que é a Sífilis?; O que a pessoa com sífilis pode sentir ou apresentar?; $\mathrm{O}$ que é a sífilis congênita?; Como descobrir se você tem sífilis?; Como você pode evitar a Sífilis Congênita?; Como é o tratamento da Sífilis?; Qual a importância do tratamento do parceiro?; Vamos resumir as informaçóes da cartilha por meio de Perguntas e Respostas?; Fechamento da cartilha; Tem alguma dúvida? Anote aqui! Para tornar a cartilha ainda mais atrativa e aproximá-la 
da realidade do público-alvo, criou-se personagens representando uma gestante com o seu companheiro e uma enfermeira, os quais estabelecem diálogo/ interação entre eles e com o leitor. Elaborou-se a cartilha em tamanho de papel A5 (148x210 mm), contendo 22 páginas em sua versão pré-validação e 25 pós-validação, sendo 14 páginas destinadas ao conteúdo, 5 pré-textuais e 6 pós-textuais. Na figura 1 são apresentadas algumas páginas da versão final da cartilha.

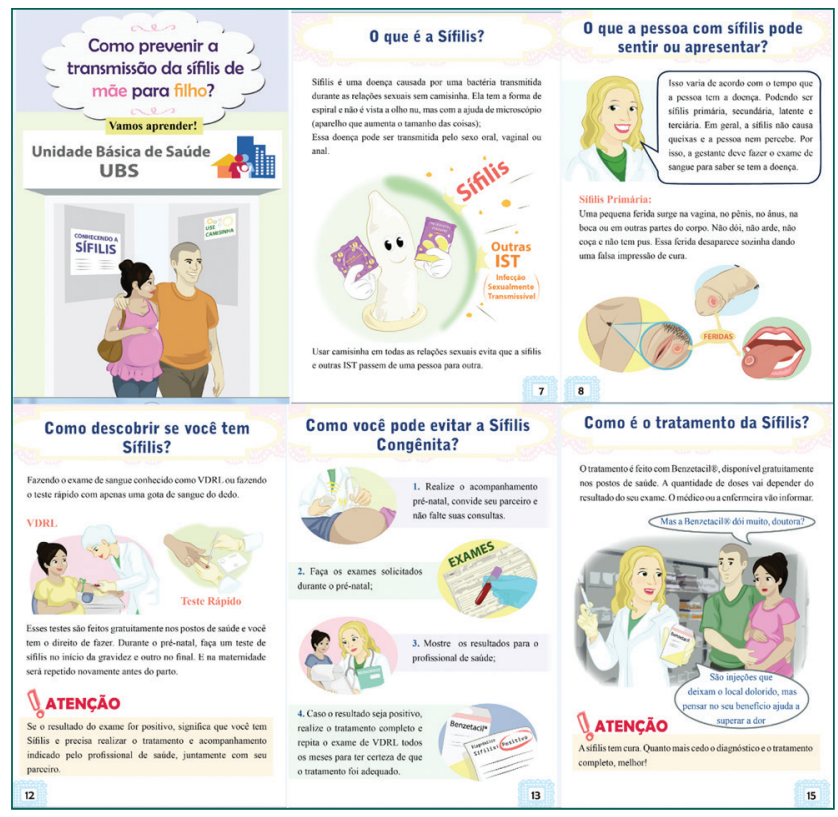

Figura 1. Páginas da Cartilha intitulada "Como prevenir a transmissão da sífilis de mãe para filho? Vamos aprender!"
$\mathrm{Na}$ fase de validação de aparência e conteúdo, verificou-se que a maioria das páginas da cartilha obteve IVC superior a 0,80, excetuando-se a página referente ao tratamento da sífilis, em relação à clareza da linguagem, sendo realizadas mudanças na linguagem a partir das recomendações dos juízes (Tabela 1).

Nas três dimensões, a média do IVC apresentou valores superiores a 0,8 , validando os conteúdos da cartilha educativa. Tendo um IVC global da cartilha de 0,96, sendo bastante satisfatório e possibilitando considerá-la validada quanto ao conteúdo. Em relação ao Alfa de Cronbach total da cartilha, obteve-se um valor de 0,955 , demonstrando excelente homogeneidade entre as respostas dos participantes.

Além disso, os juízes fizeram sugestôes pertinentes em relação à cartilha, sendo as principais: substituição de termos técnicos; reformulação e adição de ilustrações; simplificação e reelaboração de frases para tornar a linguagem mais clara; definição de siglas ou termos técnicos necessários; adição de algumas informaçôes que julgaram necessário, dentre outras.

Quanto à análise segundo SAM, a avaliação geral e a de cada item isoladamente revelou que o material foi considerado "superior" $(89,6 \%)$.

Para a validação com o público-alvo, contou-se com a participação de seis gestantes e cinco puérperas, as quais avaliaram a cartilha de forma positiva,

Tabela 1. Distribuição do IVC, teste de distribuição binomial dos itens e Alfa de Cronbach das dimensões clareza da linguagem, pertinência prática e relevância teórica de cada página da cartilha educativa

\begin{tabular}{|c|c|c|c|c|c|c|c|c|c|}
\hline & \multicolumn{3}{|c|}{ Clareza da Linguagem } & \multicolumn{3}{|c|}{ Pertinência Prática } & \multicolumn{3}{|c|}{ Relevância Teórica } \\
\hline & IVC * & $\begin{array}{c}\text { Teste binomial } \\
\text { (p-value) }\end{array}$ & $\begin{array}{l}\text { Alfa de } \\
\text { Cronbach }\end{array}$ & IVC * & $\begin{array}{l}\text { Teste binomial } \\
\text { (p-value) }\end{array}$ & $\begin{array}{c}\text { Alfa de } \\
\text { Cronbach }\end{array}$ & IVC * & $\begin{array}{l}\text { Teste binomial } \\
\text { (p-value) }\end{array}$ & $\begin{array}{l}\text { Alfa de } \\
\text { Cronbach }\end{array}$ \\
\hline & & & 877 & & & 904 & & & ,904 \\
\hline Capa & 0,91 & 0,154 & & 0,95 & 0,048 & & 0,95 & 0,048 & \\
\hline Apresentação & 0,95 & 0,048 & & 0,91 & 0,154 & & 0,95 & 0,048 & \\
\hline Página 7/Definição de sífilis & 0,95 & 0,048 & & 1 & 0,007 & & 1 & 0,007 & \\
\hline Página 8/Sinais e sintomas & 0,95 & 0,048 & & 1 & 0,007 & & 1 & 0,007 & \\
\hline Página 9/Sinais e sintomas & 0,91 & 0,154 & & 1 & 0,007 & & 1 & 0,007 & \\
\hline Página 10/Definição de sífilis congênita & 0,82 & 0,543 & & 1 & 0,007 & & 1 & 0,007 & \\
\hline Página11/Diagnóstico & 1 & 0,007 & & 1 & 0,007 & & 1 & 0,007 & \\
\hline Página12/Prevenção & 1 & 0,007 & & 1 & 0,007 & & 1 & 0,007 & \\
\hline Página13/Prevenção & 0,95 & 0,048 & & 0,95 & 0,048 & & 0,95 & 0,048 & \\
\hline Página14/Tratamento & 0,77 & 0,457 & & 0,91 & 0,154 & & 0,91 & 0,154 & \\
\hline Página15/Tratamento do parceiro & 0,86 & 0,332 & & 1 & 0,007 & & 1 & 0,007 & \\
\hline Página 16/Perguntas e respostas & 0,95 & 0,048 & & 1 & 0,007 & & 1 & 0,007 & \\
\hline Página 17/Perguntas e respostas & 0,91 & 0,154 & & 1 & 0,007 & & 1 & 0,007 & \\
\hline Página 18/Frase final & 0,95 & 0,048 & & 0,95 & 0,048 & & 0,95 & 0,048 & \\
\hline
\end{tabular}

IVC $^{*}=$ I-CVI 
obtendo $100 \%$ de concordância quanto à clareza e relevância em todas as páginas. Quando questionadas acerca do grau de relevância, todas as páginas foram classificadas como muito relevantes. Dessa forma, teve-se um IVC global com valor de 1,00.

No que se refere à avaliação do instrumento relativo à compreensão, atratividade, autoeficácia, aceitação cultural e persuasão do material educativo, houve excelentes resultados a partir da análise das respostas das participantes, conforme apresentados na tabela 2 .

Logo, verifica-se que se trata de um material educativo confiável e validado para se aplicar com as gestantes visando à prevençáo da transmissão ver-

Tabela 2. Distribuição das respostas obtidas pelo instrumento dissertativo aplicado com o público-alvo segundo os domínios de avaliação da cartilha educativa

\begin{tabular}{|c|c|c|}
\hline Domínios $(n=11)$ & $\operatorname{Sim}_{n(\%)}$ & $\begin{array}{l}\mathrm{Não} \\
\mathrm{n}(\%)\end{array}$ \\
\hline \multicolumn{3}{|l|}{ Compreensão } \\
\hline Comente sobre o que fala a cartilha & 11(100) & -- \\
\hline Você pode dizer quais os riscos da sífilis na gestação? & $11(100)$ & -- \\
\hline $\begin{array}{l}\text { Você pode citar os cuidados que devem ser realizados } \\
\text { para evitar a sífilis congênita? }\end{array}$ & $11(100)$ & -- \\
\hline Existem partes na cartilha que você não entendeu? & -- & $11(100)$ \\
\hline \multicolumn{3}{|l|}{ Atratividade } \\
\hline Você tem vontade de ler a cartilha até o fim? & $11(100)$ & -- \\
\hline \multicolumn{3}{|l|}{ Autoeficácia } \\
\hline Você acredita que pode seguir o que a cartilha mostra? & $11(100)$ & -- \\
\hline $\begin{array}{l}\text { Você necessita saber mais alguma coisa para seguir a } \\
\text { explicação da cartilha? }\end{array}$ & $1(9,1)$ & $10(90,9)$ \\
\hline \multicolumn{3}{|l|}{ Aceitação cultural } \\
\hline $\begin{array}{l}\text { Tem algo nessa cartilha que você achou agressivo, ruim } \\
\text { ou incômodo? }\end{array}$ & -- & $11(100)$ \\
\hline \multicolumn{3}{|l|}{ Persuasão } \\
\hline $\begin{array}{l}\text { Você pretende seguir as informações da cartilha para evitar } \\
\text { a sífilis na gestação e a transmissão para o seu bebê? }\end{array}$ & $11(100)$ & -- \\
\hline $\begin{array}{l}\text { Você acha que, caso tenha que informar alguma } \\
\text { mulher como evitar a transmissão da sífilis para o bebê, } \\
\text { informaria conforme mostra a cartilha? }\end{array}$ & $11(100)$ & -- \\
\hline
\end{tabular}

tical da sífilis. Quanto à avaliação do índice de legibilidade do texto da cartilha, classificou-se a leitura dos seus domínios como "fácil" ou "muito fácil", tendo os resultados do ILF variando entre 59 e 78.

Por fim, avaliaram-se os efeitos no CAP das gestantes após a aplicação da cartilha educativa. Conforme apresentado na tabela 3, verificou-se que um número significativo de mulheres, 10 (24,4\%), apresentou um conhecimento inadequado no pré-teste. Entretanto, após a intervenção educativa, houve aumento do conhecimento em todas as gestantes, tanto no pós-teste imediato, 41 (100\%), como no pós-teste do $7^{\circ}$ dia, 38 (100\%), sendo a diferença entre as médias de adequação do nível de conhecimento estatisticamente significativa.

Verificou-se que, previamente, a maioria das mulheres apresentou uma atitude adequada. Entretanto, não se identificou associação estatisticamente significativa com a prática antes da intervenção $(p=0,347)$. Fato que pode ser observado na predominância de mulheres com uma atitude adequada perante a prevenção da transmissão vertical da sífilis, mas que na prática não necessariamente apresentam açóes positivas.

Vale salientar que se avaliou a prática apenas no pré-teste e no pós-teste do $7^{\circ} \mathrm{dia}$, visto que não seria viável investigá-la logo após a intervenção, uma vez que não teria tempo suficiente para haver mudanças. Dessa forma, identificou-se um número significativo, 19 (46,3\%), com uma prática inadequada no pré-teste. Entretanto, após a intervenção educativa, houve uma melhoria considerável, sendo estatisticamente significativa $(\mathrm{p}=0,01)$, demonstrando que a leitura da cartilha educativa se mostrou

Tabela 3. Distribuição do número de mulheres e da média de adequação do nível de CAP sobre a prevenção da transmissão vertical da sífilis, antes da intervenção com a leitura da cartilha educativa, imediatamente e sete dias após a intervenção

\begin{tabular}{|c|c|c|c|c|c|c|c|}
\hline & $\begin{array}{l}\text { Pré-teste } \\
\mathrm{n}(\%)\end{array}$ & $\begin{array}{c}\text { Pós-teste } \\
\text { Imediato } \\
\text { n(\%) }\end{array}$ & $\begin{array}{l}\text { Diferença entre as } \\
\text { médias }\end{array}$ & $p$-value ${ }^{\star}$ & $\begin{array}{c}\text { Pós-teste } 7^{\circ} \text { dia } \\
\mathrm{n}(\%)\end{array}$ & $\begin{array}{l}\text { Diferença entre as } \\
\text { médias }\end{array}$ & p-value ${ }^{\star}$ \\
\hline Conhecimento & & & 0,24 & 0,01 & & 0,18 & 0,005 \\
\hline Adequado & $31(75,6)$ & $41(100)$ & & & $38(100)$ & & \\
\hline Inadequado & $10(24,4)$ & -- & & & -- & & \\
\hline Atitude & & & 0,24 & 0,32 & & 0,26 & 0,32 \\
\hline Adequada & $40(97,6)$ & $41(100)$ & & & $38(100)$ & & \\
\hline Inadequada & $1(2,4)$ & -- & & & -- & & \\
\hline Prática & & & & & & 0,31 & 0,01 \\
\hline Adequada & $22(53,6)$ & -- & & & $35(92,1)$ & & \\
\hline Inadequada & $19(46,4)$ & -- & & & $3(7,9)$ & & \\
\hline
\end{tabular}

*Teste t de Student 
efetiva para promover mudanças comportamentais, principalmente no que se refere à adoção de prática sexual saudável.

\section{Discussão}

As tecnologias educativas são ferramentas criativas, confiáveis e de utilidade para a educação em saúde, contribuindo diretamente na melhoria do processo de ensino-aprendizagem e incentivando práticas saudáveis. ${ }^{(24,25)}$

Considera-se que a habilidade para realizar o autocuidado, depende, em parte, da capacidade de leitura e compreensão de informaçóes de saúde. Nesse contexto, a informação escrita tem sido utilizada como estratégia complementar para a educação em saúde. ${ }^{(26)}$

A partir da elaboração de materiais educativos de qualidade, viabiliza-se a realização de intervençóes educativas pautadas em saberes estruturados e informaçóes direcionadas à clientela. ${ }^{(25)}$ Em estudo quase-experimental, identificou-se que houve diferença significativa entre os grupos na fase de pós-teste, com resultado superior de aprendizagem cognitiva para o grupo experimental, que participou de atividade educativa com o uso de uma cartilha sobre cuidados ao bebê prematuro. ${ }^{(27)}$

Compreende-se que o conhecimento em saúde é requisito fundamental para o autocuidado, o qual depende do empoderamento do indivíduo, que precisa conhecer as açóes necessárias para a prevenção de um determinado agravo, julgá-las importantes e ter consciência e motivação para adquirir novos hábitos de vida. Portanto, ressalta-se que o conhecimento é importante, porém não necessariamente é preditor de autocuidado. Estudo que objetivou identificar o CAP dos pacientes em hemodiálise sobre autocuidado com fístula arteriovenosa (FAV) verificou que o conhecimento e a atitude podem influenciar a prática do cliente em relação aos cuidados com a fístula. ${ }^{(28)}$

No contexto da sífilis na gestação, verifica-se um deficit no conhecimento das gestantes acerca de suas repercussóes para a saúde materno-fetal, demonstrando, assim, a necessidade de novas tecnologias que sejam eficazes na sensibilização e promoção da melhoria do conhecimento, atitude e prática das gestantes quanto à prevenção da transmissão vertical da sífilis, promovendo, dessa forma, o seu empoderamento e possibilitando que as mesmas possam modificar sua percepção de saúde e adotar práticas de promoção da saúde, colaborando para um maior controle desse agravo durante a gestação.

Sabe-se que o conhecimento é inerente à prevenção e à adesão ao tratamento da sífilis, e o seu desconhecimento torna a problemática da doença ainda maior, ocasionando sentimentos e atitudes que dificultam o seu processo de prevenção e cura. ${ }^{(29)}$

Ademais, constata-se que a utilizaçáo de cartilhas educativas tem sido eficaz para promover a melhoria do conhecimento, atitude e prática dos leitores. Ensaio clínico randomizado verificou que as gestantes do grupo de intervenção quando comparadas ao grupo controle apresentaram adequabilidade do conhecimento, atitude e prática sobre o uso dos alimentos regionais com aumento da prevalência do nível adequado no sétimo e trigésimo dia após a intervenção. ${ }^{(2)}$

Como limitação deste estudo, tiveram-se o tamanho amostral e a aplicação da intervenção educativa em apenas uma unidade de saúde, o que não pode ser considerado suficiente para generalizar os achados e ser representativo às mulheres grávidas do Brasil.

\section{Conclusão}

A cartilha educativa mostrou-se como material validado quanto à aparência e conteúdo, demonstrando que o material construído é confiável e validado para se aplicar com as gestantes durante a assistência pré-natal visando à prevenção da transmissão vertical da sífilis. Ademais, a intervenção educativa baseada na sua leitura e disponibilização melhorou o conhecimento e a prática das participantes, e essas mudanças permaneceram após sete dias da intervenção.

\section{Colaborações}

Costa CC, Gomes LFS, Teles LMR, Mendes IC, Oriá MOB e Damasceno AKC contribuíram com 
a concepção do projeto, análise e interpretação dos dados, redação do artigo, revisão crítica relevante do conteúdo intelectual e aprovação final da versão a ser publicada.

\section{Referências}

1. Brasil. Ministério da Saúde. Secretaria de Vigilância em Saúde. Departamento de DST, Aids e Hepatites Virais. Boletim Epidemiológico - Sífilis [Internet]. Brasília (DF): Ministerio da Saúde; 2018 [citado 2019 Jan 26]; 49(45):1-48. Disponível em: http://www.aids.gov.br/ pt-br/pub/2018/boletim-epidemiologico-de-sifilis-2018

2. Oliveira SC, Fernandes AF, Vasconcelos EM, Ximenes LB, Leal LP, Cavalcanti AM, Lopes MV. Efeito de uma intervenção educativa na gravidez: ensaio clínico randomizado em cluster. Acta Paul Enferm. 2018; 31(3):291-8.

3. Siddharthan T, Rabin T, Canavan ME, Nassali F, Kirchhoff P, Kalyesubula $\mathrm{R}$, Knauf $\mathrm{F}$. Implementation of patient-centered education for chronicdisease management in Uganda: an effectiveness study. PLoS One. 2016; 11(11): e0166411.

4. Echer IC. The development of handbooks of health care guidelines. Rev Lat Am Enfermagem. 2005; 13(5): 754-7.

5. Brasil. Ministério da Saúde. Secretaria de Vigilância em Saúde. Programa Nacional de DST/AIDS. Diretrizes para controle da sífilis congênita: manual de bolso [Internet]. Brasília (DF): Ministério da Saúde; 2006 [citado 2019 Jun 06]. Disponível em: http://bvsms. saude.gov.br/bvs/publicacoes/manual_sifilis_bolso.pdf

6. Brasil. Ministério da Saúde. Plano Operacional para Redução da Transmissão Vertical do HIV e da Sífilis [Internet]. Brasília (DF): Ministério da Saúde; 2007 [citado 2019 Jun 6]. Disponível em: http:// bvsms.saude.gov.br/bvs/publicacoes/plano_operacional_WEB.pdf

7. Brasil. Ministério da Saúde. Secretaria de Vigilância em Saúde. Programa Nacional de DST e Aids. Protocolo para a prevenção de transmissão vertical de HIV e sífilis: manual de bolso [Internet]. Brasília (DF): Ministério da Saúde; 2007 [citado 2019 Jun 6]. Disponivel em: http://www.aids.gov.br/pt-br/pub/2006/protocolo-para-prevencaode-transmissao-vertical-de-hiv-e-sifilis-2007-manual-de-bolso

8. Brasil. Ministério da Saúde. Secretaria de Vigilância em Saúde. Programa Nacional de DST/AIDS. Sífilis: Estratégias para Diagnóstico no Brasil [Internet]. Brasília (DF): Ministério da Saúde; 2010. [citado 2019 Jun 6]. Disponível em: http://bvsms.saude.gov.br/bvs/ publicacoes/sifilis_estrategia_diagnostico_brasil.pdf

9. Brasil. Ministério da Saúde. Secretaria de Vigilância em Saúde. Departamento de DST, Aids e Hepatites Virais. Caderno de boas práticas: 0 uso da penicilina na Atenção Básica para a prevenção da sífilis congênita no Brasil. Brasília (DF): Ministério da Saúde; 2015. [citado 2019 Jun 6]. Disponível em: http://bvsms.saude.gov.br/bvs/ publicacoes/penicilina_para_prevencao_sifilis_congenita\%20_brasil. pdf

10. Doak CC, Doak LG, Root JH. Teaching patients with low literacy skills. 2a ed. Philadelphia: J.B. Lippincott; 1996.
11. Moreira MF, Nóbrega MM, Silva MI. Comunicação escrita: contribuição para a elaboração de material educativo em saúde. Rev Bras Enferm. 2003; 56(2):184-8.

12. Lopes MV, Silva VM, Araujo TL. Methods for establishing the accuracy of clinical indicators in predicting nursing diagnoses. Int J Nurs Knowl. 2012; 23(3):134-9.

13. Jasper MA. Expert: a discussion of the implications of the concept as used in nursing. J Adv Nurs. 1994; 20(4):769-76.

14. Pasquali L. Instrumentação psicológica: fundamentos e práticas. Porto Alegre: Artmed; 2010. 560p.

15. Polit DF, Beck CT. Fundamentos de pesquisa em enfermagem: avaliação de evidências para a prática da enfermagem. 7a ed. Porto Alegre: Artmed; 2011.

16. Norwood S. Research strategies for advanced practice nurses. Upper Saddle River (NJ): Prentice Hall Health; 2006.

17. Lobiondo-Wood G, Haber J. Pesquisa em enfermagem: métodos, avaliação crítica e utilização. 8a ed. Rio de Janeiro: Guanabara Koogan; 2014.

18. Sousa CS, Turrini RN, Poveda VB. Tradução e adaptação do instrumento "Suitability Assessment Of Materials" (SAM) para o português. Rev Enferm UFPE On Line. 2015; 9(5):7854-61.

19. Nascimento LA, Rodrigues AP, Joventino ES, Vieira NF, Pinheiro PN, Ximenes LB. Validation of educational video to promote self-efficacy in preventing childhood diarrhea. Health. 2015;7(2):192-200.

20. Pasquali L. Psicometria: teoria e aplicação. Brasília: Ed. UnB; 1998.

21. Vianna HM. Testes em educação. São Paulo: IBRASA; 1982.

22. Fonseca LM, Scochi CGS, Rocha SM, Leite AM. Cartilha educativa para orientação materna sobre os cuidados com o bebê prematuro. Rev Lat Am Enfermagem. 2004;12(1):65-75.

23. Martins TB, Ghiraldelo CM, Nunes MG, Oliveira ON. Readability formulas applied to textbooks in brazilian Portuguese. São Paulo: Universidade de São Paulo; 1996. (Notas do ICMC-USP, Série Computação).

24. Interaminense IN, Oliveira SC, Leal LP, Linhares FM, Pontes CM. Tecnologias educativas para promoção da vacinação contra 0 papilomavírus humano: revisão integrativa da literatura. Texto Contexto Enferm. 2016; 25(2):e2300015.

25. Barbosa EM, Sousa AA, Vasconcelos MG, Carvalho RE, Oriá MO, Rodrigues DP. Tecnologias educativas para promoção do (auto) cuidado de mulheres no pós-parto. Rev Bras Enferm. 2016;69(3): 582-90.

26. Moura DJ, Moura NS, Menezes LC, Barros AA, Guedes MV. Construção de cartilha sobre insulinoterapia para crianças com diabetes mellitus tipo 1. Rev Bras Enferm. 2017; 70(1): 7-14.

27. Silva IO, Aredes ND, Bicalho MB, Delácio NC, Mazzo LL, Fonseca LM. Cartilha sobre o prematuro como tecnologia educacional para família: estudo quase experimental. Acta Paul Enferm. 2018; 31(4): 334-41.

28. Pessoa NR, Linhares FM. Conhecimento, atitude e prática sobre a fístula arteriovenosa. Esc Anna Nery. 2015; 19(1): 73-9.

29. Vasconcelos MI, Oliveira KM, Magalhães AH, Guimarães RX, Linhares MS, Queiroz MV, Albuquerque IM. Syphilis in pregnancy: strategies and challenges of nurses of primary care for treat ment couple simultaneous. Rev Bras Promo Saude. 2016; 29:85-92. 